\title{
SUPPLEMENTAL ABSTRACTS
}

PREVENTION OF FATAL PULMONARY THROMBOEMBOLISM BY HEPARIN PROPHYLAXIS AFTER SURGERY FOR HIP

FRACTURES. J.G. Sharnoff. The Mount Vernon Hospital, Mount Vernon, New York, U.S.A.

From 1960 through 1975,337 patients with surgicaliy treated acute fracture of the hip received subcutaneousiy administered aqueous heparin sodium to prevent thromboembolic episodes. Four hundred and three patients received no heparin. Their incidence of fatal pulmonary embolism was 3.5 percent. Ninety-five patients receiving the original "sma11 dose" heparin regimen from August 1960 to November 1967 had a 4.2 percent incidence of fatal thromboembolism. These had been administered heparin 8-10 hours or less before surgery. Beginning November 1967 the "small dose" heparin schedule was altered in hip fracture patients to start heparin prophylaxis immediately following hospital admission. One hundred and forty-seven patients treated with the latter schedule had 0.0 percent fatal thromboembolism with the dose modified according to a coagulation time test. The patients recelved 2,500 units on admission and every 6 hours until the day before operation. Then they were given 5,000 to 10,000 units 8 to 10 hours before surgery and 2,500 units every 6 hours after surgery until they were fully mobilized. The altered "small dose" heparin regimen adequately monitored by the blood coagulation test, the Dale and Laidlaw Coagulometer, proved highly effective as measured by fatality rates.

A LINK BETWEEN AGGREGATION OF REI CFILS AND FORNATION OF ARTIFICIAI RED-WHITE THROMBI. L. Dintenfass. Haemorheology Department, Medical Research, Kanematsu Memorial Institute, Sydney Hospital, Syaney 2000; and Department of Medioine, University of Sydney, Sydney 2006, Australia.

While aggregation of red cells appears to be related to coagulation, in particular to formation of red clots, it has not been proven whether this j.s the case in respect of arterial thrombi. To explore this point, a study of aggregation of red cells (estimated from erythrocyte sedimentation rates defined in Westergren tubes on EDTA blood, corrected for plasma viscosity and adjusted to haematocrit of 30\%) and of apparent viscosity of artificial in vitro red/white thrombi (obtained in VFTV - variable frequency thrombo viscometer) has been carried out on 500 subjects. These comprised patients with diabetes, post-myocardial infarction states, melanoma, and normals. Only in normals a correlation of significance $\mathrm{P}<0.001$ has been found. In all disease groups no significant correlation was noted. However, a comparison of the slopes, elevations and residual variance of regressions showed highly significant differences between 'aggregation of red celis - apparent viscosity of red/white thrombus' functions for different disease groups (up to $P<0.005)$, and for different $A B O$ blood groups within any single disease group (up to Pro.001). It appears that a link between aggregation of red cells and the apparent viscosity of artificial red/white thrombus does not form a single general pattern: it is different in different groups and subdivisions. 